\title{
ACTH-secreting pituitary carcinoma with TP53, NF1, ATRX and PTEN mutations Case report and review of the literature
}

\author{
Piotr Sumislawski ${ }^{1}$. Roman Rotermund ${ }^{1}$ - Silke Klose ${ }^{2}$ - Anne Lautenbach ${ }^{3}$ - Annika K. Wefers ${ }^{4,5}$. \\ Celina Soltwedel ${ }^{4} \cdot$ Behnam Mohammadi $^{4}$. Frank Jacobsen ${ }^{6} \cdot$ Christian Mawrin $^{7} \cdot$ Jörg Flitsch $^{1}$. \\ Wolfgang Saeger (i) ${ }^{4}$
}

Received: 12 July 2021 / Accepted: 14 November 2021 / Published online: 16 February 2022

(c) The Author(s) 2021

Pituitary carcinoma (PC) is a very rare tumor entity of the sella turcica, representing $0.1-0.5 \%$ of all PitNETs tumors [1-5]. Based on the WHO Classification, it is defined as pituitary tumor with confirmed craniospinal and/or systemic metastases [6]. Most of them present CNS only $(45,2 \%)$ or extra CNS $(38,7 \%)$ metastases. Synchronous extra- and CNS metastases are less common $(16,1 \%)$ [7]. It is not known whether the tumors develop predominantly from PitNETs after a longer clinical course or de novo [8]. PCs can be hormonally inactive or active (ACTH-, PRL-, GH-, TSH- FSH-, LH-secreting), but far most of them are ACTHor PRL-secreting tumors [8, 9]. There is little known about the genetic background of this tumor entity, because most of the information comes from case reports and singular larger case series. $A T R X[10,11], C D K N 2 A[11], C D K N 2 B$

These authors contributed equally: Piotr Sumislawski, Roman Rotermund, Jörg Flitsch, Wolfgang Saeger

Wolfgang Saeger

w.saeger@uke.de

1 Department of Neurosurgery, University Medical Center Hamburg-Eppendorf, Martinistr.52, 20246 Hamburg, Germany

2 Department of Internal Medicine/Endocrinology, Otto von Guericke Universität Magdeburg, Magdeburg, Germany

3 III. Department of Medicine, University Medical Center HamburgEppendorf, Hamburg, Germany

4 Institute of Neuropathology, University Medical Center HamburgEppendorf, Hamburg, Germany

5 Mildred Scheel Cancer Career Center HaTriCS4, University Medical Center Hamburg-Eppendorf, Hamburg, Germany

6 Institute of Pathology, University Medical Center HamburgEppendorf, Martinistr, Hamburg, Germany

7 Institute of Neuropathology, University of Magdeburg, Magdeburg, Germany
[11], SDHB [12], TP53 [11, 13] mutations have been identified in primary [13] and $A T R X$ [10, 11], CDKN2A [11], CDKN2B [11], H-Ras [14] mutations in metastatic tumors. $\mathrm{MSH} 2$ germline mutation was described in one case report [15]. PTEN mutations were reported without localization [16]. The tumors have a poor prognosis with a $66 \%$ mortality rate after 1 year and up to $80 \%$ after 8 years $[1,17]$.

Treatment options include surgery, chemotherapy, hormonal therapy, and/or radiotherapy. There are many different chemotherapeutic protocols. To the most commonly used chemotherapeutics include temozolomide, CCNU + 5-fluoruracil. Especially in ACTH-secreting PCs other agents, which lower ACTH and cortisol secretion, are additionally used. As most ACTH-secreting tumors express somatostatin receptor type 5 , pasireotide as potent somatostatin analog with high affinity to somatostatine receptor type 5 showed significant suppression of ACTH and cortisol secretion [18]. Mitotane and ketoconazole as steroidogenesis inhibitors can support the treatment by reducing the cortisol levels and present an alternative to bilateral adrenalectomy [10, 19, 20].

In this paper, we present the case of an ACTH-secreting $\mathrm{PC}$ with liver and thoracic vertebrae metastases. For further characterization, DNA from the primary tumor and liver metastases were isolated. DNA sequencing revealed TP53, NF1 mutations in the primary tumor, and TP53, NF1, PTEN, and ATRX mutations in liver metastases. Based on our results and the literature, we discuss the genetic origin of PC and the molecular principles of their metastases (Fig. 1).

\section{Case report}

A 53-years old male was referred for repeated surgery of a persisting pituitary neuroendocrine tumor (PitNET) with a 2-year history of arterial hypertension and diabetes mellitus, clinical (Fig. 2), and laboratory signs (Table 1) of Cushing's 
Fig. 1 Graphical abstract

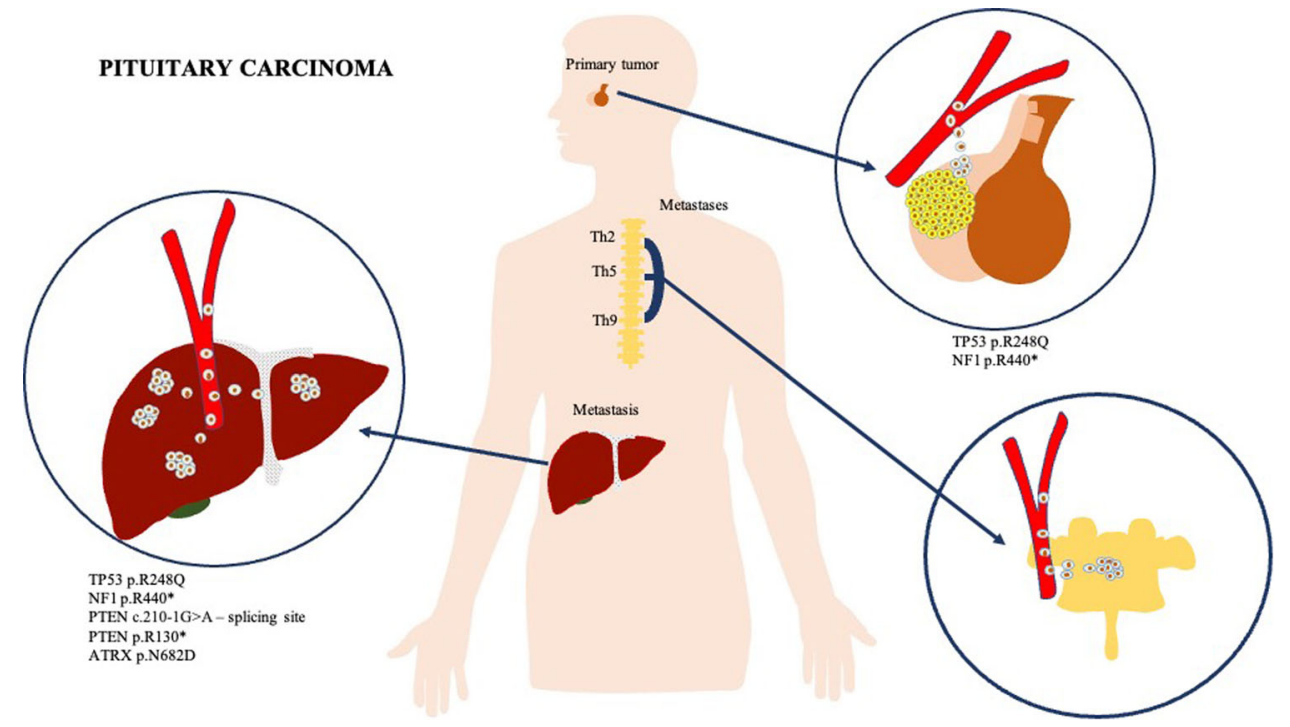

Table 1 Pre- and postoperative laboratory results with reference ranges

\begin{tabular}{llll}
\hline Test & $\begin{array}{l}\text { Result } \\
\text { preoperative }\end{array}$ & $\begin{array}{l}\text { Results 3rd } \\
\text { postoperative day }\end{array}$ & Reference range \\
\hline ACTH & 3534 & 3360 & $\sim 46 \mathrm{ng} / \mathrm{l}$ \\
Cortisol & 1621 & 1835 & $52,7-224 \mu \mathrm{g} / 1$ \\
GH & $<0.15$ & $<0.15$ & $\sim 16 \mathrm{mU} / 1$ \\
IGF-1 & 55.6 & 50.3 & $48-209 \mu \mathrm{g} / \mathrm{l}$ \\
TSH & 0,04 & 0.04 & $0.55-4.76 \mathrm{mU} / 1$ \\
fT4 & 16.3 & 11.5 & $11.5-22.7 \mathrm{pmol} / 1$ \\
fT3 & 3.0 & 2.1 & $4.5-6.5 \mathrm{pmol} / 1$ \\
FSH & 0.6 & 0.5 & $1.4-18.1 \mathrm{U} / 1$ \\
LH & $<0.07$ & $<0.07$ & $1.5-9.3 \mathrm{U} / 1$ \\
Testosterone & 3.87 & 3.13 & $0.86-7.88 \mu \mathrm{g} / 1$ \\
Prolactin & 2.1 & 1.8 & $2.1-17.7 \mu \mathrm{g} / \mathrm{l}$ \\
Potassium & 2.5 & 3.2 & $3.5-4.6 \mathrm{mmol} / 1$ \\
Sodium & 136 & 137 & $135-145 \mathrm{mmol} / 1$ \\
\hline
\end{tabular}

disease, hypopituitarism and hypokalemia. Eight months before admission, the patient had been operated at another neurosurgical center with initial diagnosis of ACTH-secreting PitNET with strongly increased proliferation. After operation, the patient received adjuvant radiation ( $54 \mathrm{~Gy}$ ) and systemic therapy with metyrapone $(3 \mathrm{~g})$ and ketoconazole $(400 \mathrm{mg}$ ) for persisting hypercortisolism. In the initial laboratory testing, a relevant decline in cortisol and ACTH levels was seen, requiring temporary hydrocortisone replacement. Control testings after 4 months revealed tumor relapse. The ophthalmologic examination before the second surgery was unremarkable. An elective exoscopic transsphenoidal surgery was performed. Postoperatively, the patient remained neurologically intact without any signs of liquorrhea, headaches, nausea, or emesis. Laboratory testing showed further pituitary insufficiency, hypokalemia under potassium substitution, no significant improvement of cortisol and ACTH levels. There were no signs of diabetes insipidus or SIADH. Because of persistent, strongly increased ACTH and cortisol levels, a thoracic and abdominal CT and a craniospinal MRI were performed to search for ectopic sources of ACTH. They revealed multiple lesions suspicious for metastases in the liver (Fig. 3) and in the body of the thoracic vertebrae 2, 5, and 9 (Fig. 4). Sella MRI revealed normal postoperative finding without any residual tumor. The adrenal glands were massively enlarged as a result of ACTH stimulation (Fig. 3). The hepatic laboratory tests revealed elevated transaminases (AST and ALT), ALP, and especially GGT, as a sign of liver dysfunction which remained stable under treatment with ketoconazole (Table 2). A CT-guided biopsy was performed for histological assessment. Pathologic examination of the liver revealed many small nests of tumor cells, compatible with PC metastasis.

\section{Pathohistology of liver metastases}

Biopsy shows very small foci within the blood sinus and one larger focus of tumor tissue composed of densely arranged small to medium-sized cells with chromatin-rich nuclei and poor cytoplasm. Manually counted mitoses had a median value of 20 /10 HPF. Immunostains for ACTH were positive, but the transcription factor for pituitary ACTH cells (T-pit) was not expressed. Ki-67 index was very high (60\%) (Fig. 5d). p53 was expressed in nearly all tumor cell nuclei (Fig. 5f) (Table 3). ATRX expression was retained (Fig. 5h).

\section{Pathohistology of pituitary tumor}

The structure and immunostains of the pituitary tumor were very similar to the tumor in the liver. Therefore, we 
Fig. 2 Clinical examination. Hyperpigmentation of the skin predominantly in the face $(\mathbf{a}, \mathbf{b})$ and at upper extremity (c) in comparison to lower extremity (d)
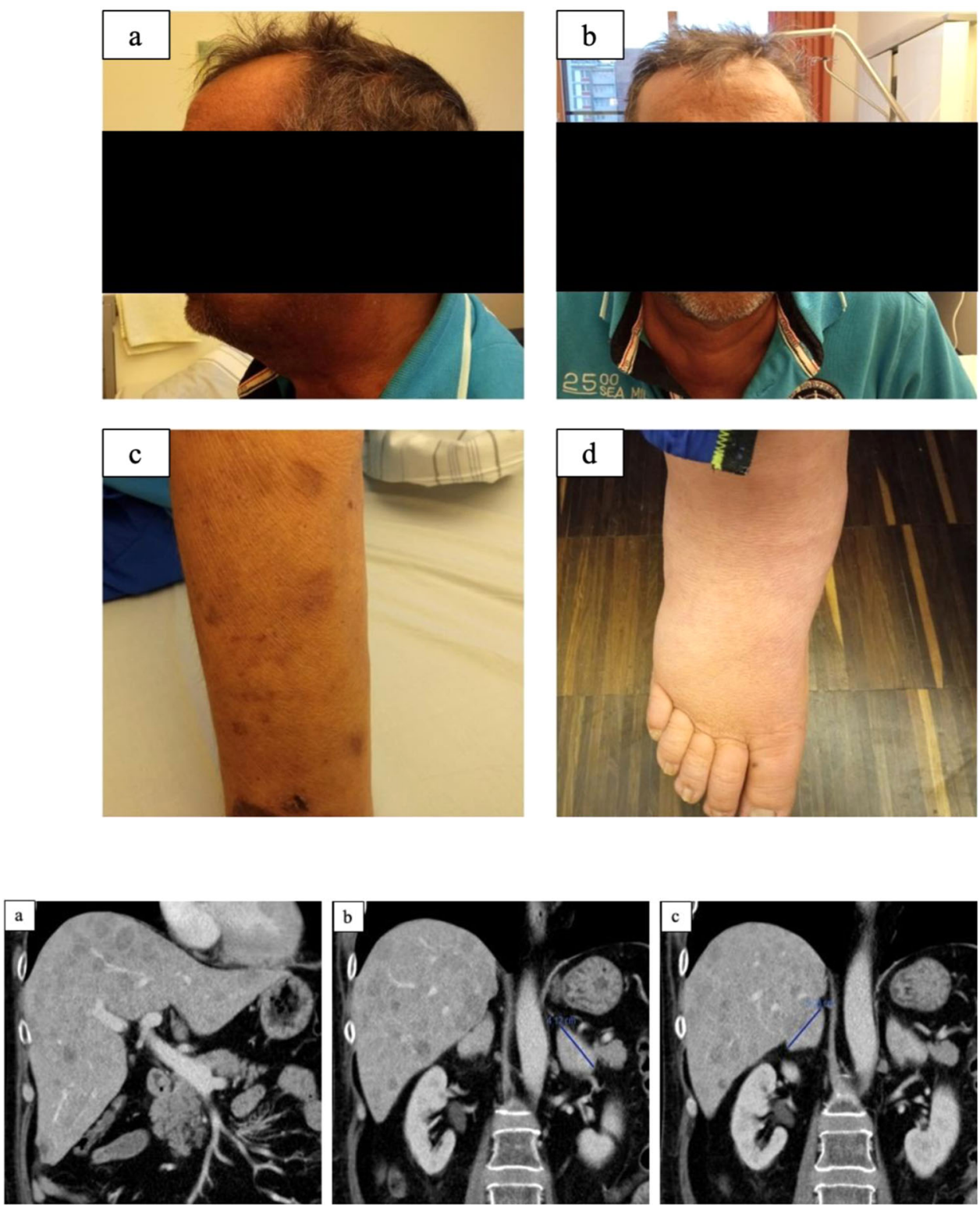

Fig. 3 Liver metastases. Liver metastasis $(\mathbf{a}-\mathbf{c})$ with massively enlarged adrenal glands $(\mathbf{b}, \mathbf{c})$
Table 2 Liver function laboratory results with reference ranges

\begin{tabular}{lcl}
\hline Test & Results & Reference range \\
\hline AST & 109 & $<50 \mathrm{U} / 1$ \\
ALT & 146 & $<50 \mathrm{U} / 1$ \\
GGT & 12888 & $<73 \mathrm{U} / 1$ \\
ALP & 223 & $46-116 \mathrm{U} / 1$ \\
\hline
\end{tabular}

can clearly state that either the tumor in the pituitary and in the liver were metastases of a somewhere else localized tumor or the pituitary tumor was the primary. This question could be answered by the expression of T-pit (Fig. $5 \mathrm{e}$ ) in the pituitary tumor since this transcription factor is the lineage marker for the pituitary ACTH cells (Fig. 5c).
ATRX expression was retained (Fig. 5g). EGFRVIII was not expressed.

\section{Next-generation-sequencing}

DNA panel sequencing of the sellar and hepatic tumors revealed the same mutations of TP53 (NM_0005465: c.743G > A, p.R248Q) and NF1 (NM_001042492.2: c. $\left.1318 \mathrm{C}>\mathrm{T}, \mathrm{p} . \mathrm{R} 440^{*}\right)$ in both tumors. Additionally, we found two PTEN mutations (NM_000314.6:c.388C > T (p. R130*) and c.210-1G > A (splice site) as well as an ATRX mutation(NM_000489.4:c.2044A > G, p.N682D) in the liver tumor only. This confirmed that the pituitary tumor was the primary while the liver tumors were metastases. 
Fig. 4 Vertebral metastases. Metastases in the vertebral bodies of Th2 (arrows) -T1 seq (a), T1 seq with contrast agent (b) and Th5, Th9 (arrows) -T1 seq (c), T1 seq with contrast agent (d)
Table 3 A summary of the staining
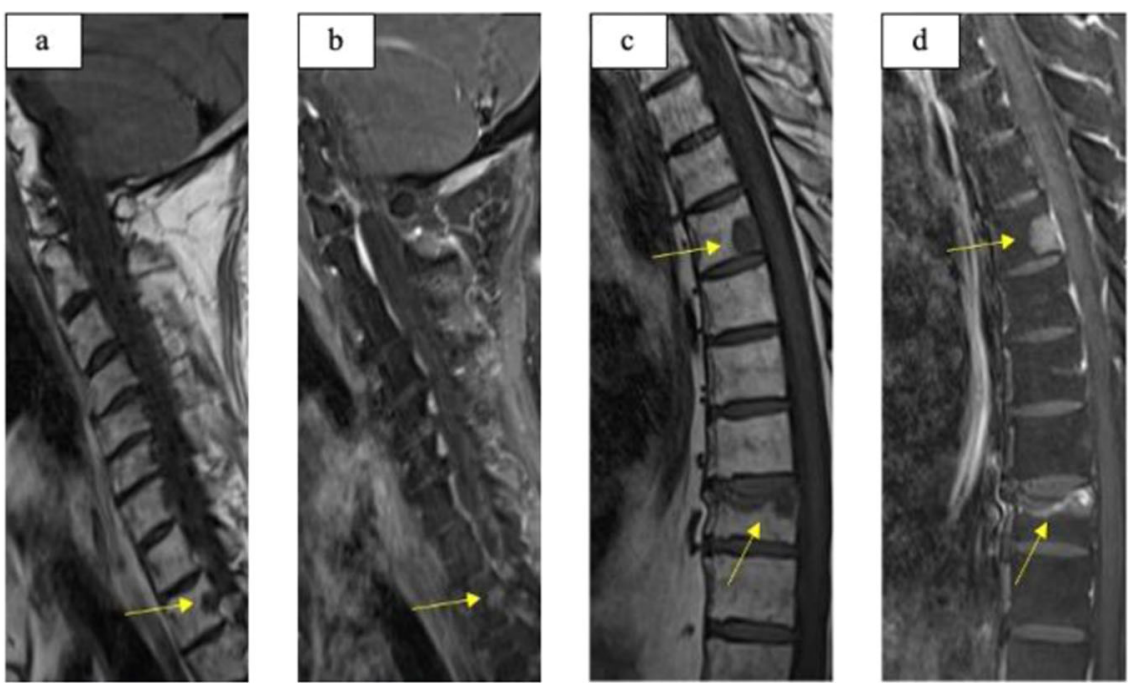

\begin{tabular}{llllllll}
\hline Tissue & ACTH & Ki-67 & Mitoses per 10 HPF & p53 & T-Pit & synaptophysin & chromogranin \\
\hline Pituitary & Strong & $60 \%$ & 20 & $\sim 100 \%$ & Positive & Strongly positive & Negative \\
Liver & Strong & $60 \%$ & 20 & $\sim 100 \%$ & Negative & Strongly positive & Strongly positive \\
\hline
\end{tabular}

\section{Sanger-sequencing}

USP8 exon 14 sequencing along with and USP48 region encompassing hotspot in USP domain revealed no mutations or deletions.

Because of multiple disseminated liver and vertebral metastases, the palliative treatment with temozolomide, mitotane, and pasireotide was started. The patient died 10 months after the first diagnosis of the pituitary tumor.

\section{Review of literature for mutation analyses}

A literature review via PubMed using the search terms 'pituitary carcinoma', 'pituitary carcinomas' combined with 'mutation' was performed. Only studies with a confirmed diagnosis of PC and information about the mutational status were included. Total number of 7 studies containing 34 patients from which only 14 revealed pathologic gene variants via gene sequencing. TP53 mutations were identified in the primary tumors $[11,13]$ (Table 4). Loss-of-function mutations of ATRX gene were described both in primary and metastatic PC $[8,11,16]$ (Tab.4). Higher incidence of ATRX mutations among recurrent comparing to primary PitNETs may indicate a possible contribution to tumor progression [21]. One patient with PC harboring a loss-offunction $S D H B$ mutation in and history of paraganglioma was described [12] (Table 4). Ras gene analysis involving $\mathrm{K}$-, $\mathrm{H}$ - and $\mathrm{N}$-Ras revealed 2 different $H$-Ras mutations in PC metastasis [14] (Table 4). A patient with Lynch Syndrome and germline $\mathrm{MSH} 2$ mutation in a $\mathrm{PC}$ was reported [15] (Table 4).

\section{Discussion}

TP53, NF1, and PTEN are well known tumor suppressor genes. $P 53$ and $N F 1$ are involved in Ras-activity regulation. p53 suppressor effect on RAS-activity is mediated by BTG2 $[22,23]$. Several different domains are responsible for apoptosis, growth repression or DNA repair [24-26]. This protein is also involved in other cellular functions such as control of cell cycle through p21 and is self-controlled by MDM2 protein. As TP53 mutations were described by primary tumors, they may be involved especially in the PC tumorigenesis. TP53 p.R248Q. mutation is localized in the DNA-binding domain (Fig. 4) and its effect can be mediated by both BTG2 and NF-кB [22].

NF1 on the other hand negatively regulates RAS pathway by inducing dephosphorylation of Ras-GTP to RasGDP [27]. This protein is made from several domains with different functions [28, 29]. NF1 p.R440*, a nonsense mutation, causes protein-truncating variant without essential domains such as Cysteine/Serine-rich domain or GTPaseactivation protein-related domain (Fig. 5).

PTEN protein is built up of different domains including phosphatase domain $[30,31]$, which is responsible for converting PI $(3,4,5) \mathrm{P}_{3}$ to $\mathrm{PI}(4,5) \mathrm{P}_{2}$ and thus antagonizing the PI3K pathway ${ }^{32}$. Both PTEN c.210-1 G > A and p.R130* mutations (Fig. 4) cause loss-of-function which can consequently activate PI3K pathway. It could then promote tumor metastases by inducing epithelial-to-mesenchymal-transition and cytoskeletal remodeling, which can at the end increase the tumor motility $[33,34]$. PTEN loss or its low expression was correlated with a higher risk of metastasis [35]. PTEN 
Table 4 Characteristics of studies included in this review

\begin{tabular}{|c|c|c|c|c|c|}
\hline Pat. No. & Gene & CDS mutation & AA mutation & $\begin{array}{l}\text { Germline }(\mathrm{G}) / \\
\text { primary tumor }(\mathrm{PT}) / \\
\text { metastasis }(\mathrm{M})\end{array}$ & Authors \& year \\
\hline 1 & \multirow[t]{8}{*}{ ATRX } & c.134_6217del & p.D45-K2027del & PT & \multirow{6}{*}{$\begin{array}{l}\text { Casar-Borota } \\
\text { et al. } 2021\end{array}$} \\
\hline 2 & & c. $748 \mathrm{C}>\mathrm{T}$ & p.Arg250Ter & PT & \\
\hline 3 & & c.6679delG c.3583delA & $\begin{array}{l}\text { p.Asp2227fs } \\
\text { p.Arg1195fs }\end{array}$ & PT & \\
\hline 4 & & $\begin{array}{l}\text { c. } 4048 \_4049 \text { delGG } \\
\text { c. } 6661 \mathrm{G}>\mathrm{T}\end{array}$ & $\begin{array}{l}\text { p.Gly1350fs p. } \\
\text { Glu2221Ter }\end{array}$ & PT & \\
\hline 4 & & c.4048_4049delGG & p.Gly1350fs & M & \\
\hline 5 & & c.595_6699del & $\begin{array}{l}\text { p.N199- } \\
\text { K2233del }\end{array}$ & PT and $\mathrm{M}$ & \\
\hline 6 & & Deletion of exon 3 to 27 & No data & $\mathrm{PT}$ and $\mathrm{M}$ & $\begin{array}{l}\text { Casar-Borota } \\
\text { et al. } 2017\end{array}$ \\
\hline 7 & & No data & No data & Not mentioned & Guo et al. 2018 \\
\hline 5 & CDKN2A & c.1_501del & p.M1-A167del & $\mathrm{PT}$ and $\mathrm{M}$ & \multirow{2}{*}{$\begin{array}{l}\text { Casar-Borota } \\
\text { et al. } 2021\end{array}$} \\
\hline 5 & CDKN2B & c.1_414del & p.M1-D138del & PT and $\mathrm{M}$ & \\
\hline 8 & \multirow[t]{3}{*}{ H-Ras } & c. $34 \mathrm{G}>\mathrm{C}$ & p.G12R & M & \multirow[t]{3}{*}{ Pei et al. 1994} \\
\hline 9 & & c. $52 \mathrm{G}>\mathrm{A}$ & p.A18T & M & \\
\hline 10 & & Codon 3 del & - & M & \\
\hline 11 & MSH2 & c.1587delA & p.E530Kfs & G & $\begin{array}{l}\text { Bengtsson et. } \\
\text { al. } 2007\end{array}$ \\
\hline 7 & PTEN & No data & No data & Not mentioned & Guo et al. 2018 \\
\hline 12 & SDHB & c. $587 \mathrm{G}>\mathrm{A}$ & p.Cys196Try & PT & $\begin{array}{l}\text { Tufton et al. } \\
2017\end{array}$ \\
\hline 2 & \multirow[t]{5}{*}{ TP53 } & c. $524 \mathrm{G}>\mathrm{A}$ & p.Arg175His & PT & \multirow{2}{*}{$\begin{array}{l}\text { Casar-Borota } \\
\text { et al. } 2021\end{array}$} \\
\hline 4 & & c. $644 \mathrm{G}>\mathrm{A}$ & p.Ser215Asn & PT & \\
\hline 7 & & No data & No data & Not mentioned & Guo et al. 2018 \\
\hline 13 & & c. $742 \mathrm{C}>\mathrm{G}$ & p.R248G & PT & \multirow{2}{*}{$\begin{array}{l}\text { Tanizaki et al. } \\
2007\end{array}$} \\
\hline 14 & & c. $404 \mathrm{G}>\mathrm{T}$ & p.C135F & PT & \\
\hline
\end{tabular}

CDS mutation coding DNA sequence mutation, AA mutation amino acid mutation. mutation however described by Guo et al. by PC, lacked basic information regarding the origin of examined sample and the localization of detected mutation [16].

ATRX is a transcriptional regulator and its mutations including loss-of-function were detected in PC $[8,11,16]$. ATRX loss-of-function may induce telomere instability and promote alternative lengthening of telomeres (ALT), as ATRX maintains their structure and function by interacting with DAXX and histone H3.3 variant [8].

Tumor cells harboring of ATRX p.N682D mutation in metastasis retained ATRX expression in immunostains (Fig. 4h), which can suggest the preserved function of ATRX protein.

USP8 and USP48 gene mutations are frequent in corticotroph PitNETs [36, 37]. Gene sequencing of USP8 and USP48 in primary tumor revealed no mutations or deletions in hotspot regions. Sbiera et al. described all USP48 mutated cases only with TP53 wildtype variant indicating that they can be mutually exclusive [37].

ATRX, p53, Ki67 immunostains may be useful in the early diagnostic of PC. Loss of ATRX expression may indicate PC in immunochemistry, as around 20\% of PC harbor loss-of-function mutations of this gene. On the other hand, increased Ki67 and p53 expression over the cut-off values Ki67 $(\geq 4 \%)$ and p53 ( $\geq 2 \%)$ suggest aggressive PiNETs and with higher values even PC [38].

NF1, TP53, and PTEN mutations lead to activation of several well-known signaling pathways (RAS, RAF, MAPK, ERK, PI3K, Akt) [22-35] (Fig. 6). From a therapeutic view, they could offer a potential goal for targeted drug therapy, as RAF-, MEK-, ERK-, PI3K- and Aktinhibitors have been successfully tested in many clinical trials [39-41]. In case of TP53 mutation novel therapeutic agents such as APR-246 converting mutant to wild type p53 or bispecific antibody against mutant p53 could be implemented in the oncological therapy [42]. For tumors with ATRX loss-of-function and following ALT process and impaired DNA repair, an epigenetic therapy applied by G-quadruplex-interacting compounds may be effective, as could restore genomic stability [43] (Fig. 7). Clinical studies including immune checkpoint inhibitors (pembrolizumab, ipilimumab, or nivolumab) by aggressive PiNETs along 
Fig. 5 Histological examination. a Pituitary tumor: HE, $250 \times$, b liver metastasis: HE (arrow: liver tissue) $440 \times$, c pituitary tumor: ACTH expression in $20 \%$ of tumor cells, $440 \times, \mathbf{d}$ metastasis: Ki-67 index 50-60\%, 440×, e pituitary tumor $\mathrm{T}$ - pit expression in nuclei, $250 \times$, f metastasis: p53 expression in all nuclei, 440×, $\mathbf{g}$ pituitary tumor: ATRX expression retained, $250 \times$, h metastasis: ATRX expression retained (right upper corner-1 liver tissue), $440 \times$
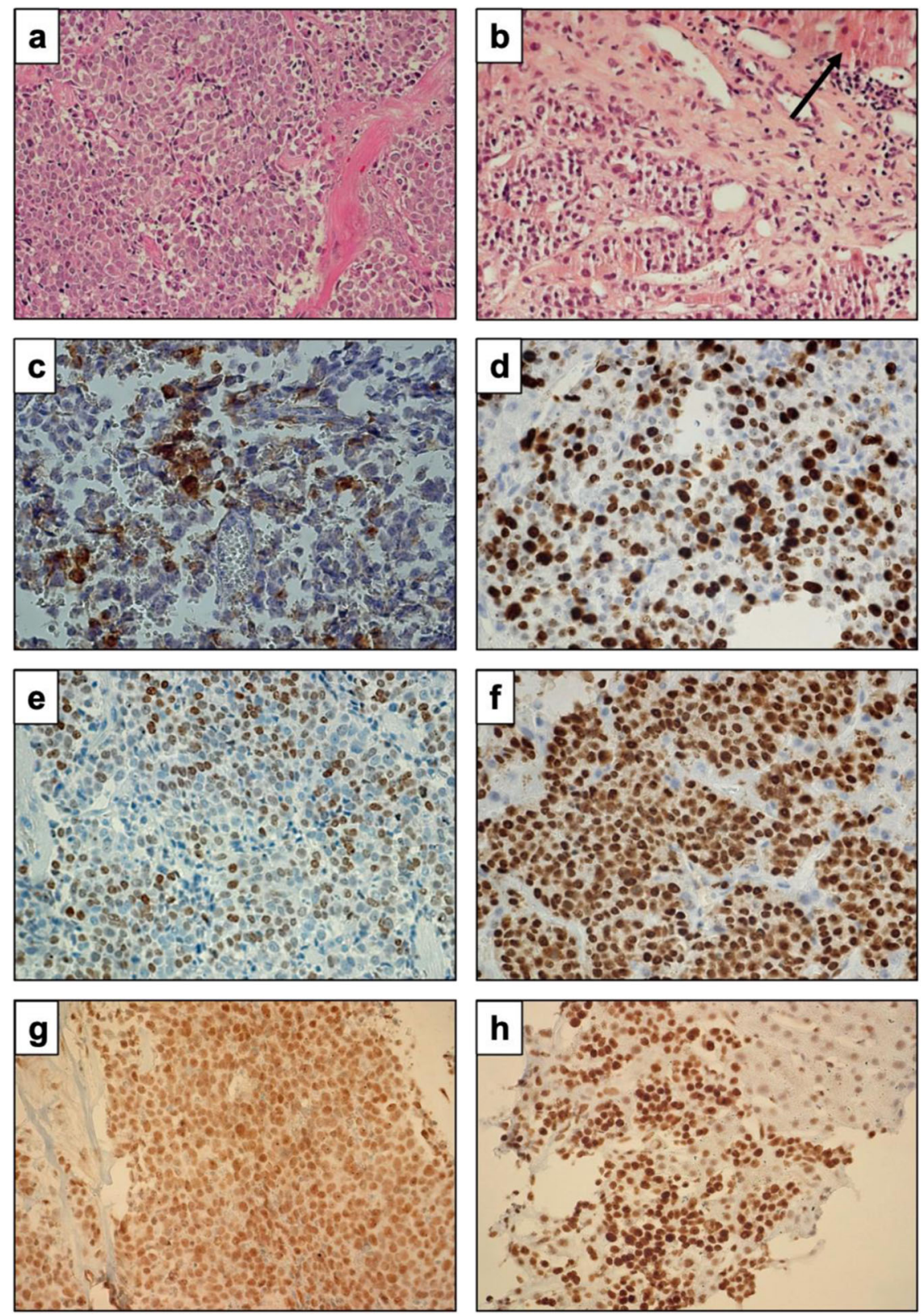

with PCs showed ambiguous results, as one patient exhibited tumor regression and another faced with tumor progression after the treatment [44]. It confirms that PCs are heterogenous group of tumors and require more complex and personalized diagnostic approach to identify the genetic drivers and to try to establish molecularly targeted therapy in the future.

\section{Conclusion}

Pituitary carcinoma(PC) is a devastating disease with high mortality rate. The molecular background for the development of this rare tumor entity and the mechanism of metastasis are unknown. There are only a few case reports and singular larger case series considering only restricted number of sequenced genes by the PC $[8,11-16]$. From our case report and review of the literature we propose special improvements of diagnostic approach in case of PC suspicion by application of NGS for at least several genes found in PC biology ATRX, CDKN2A, CDKN2B, H-Ras, NF1, PTEN, SDHB, MSH2, and TP53 genes, as well as these involved in PitNET biology e.g., USP8 or USP48. This technique may be implemented into clinical practice to detect the genetic drivers for planning targeted therapies for PC as several identified gene mutations are potential targets for pharmacological therapy. 


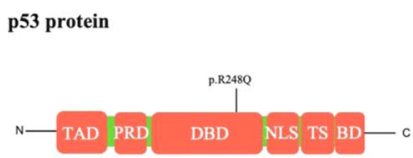

PTEN protein

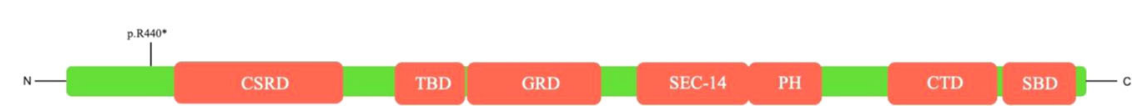

Fig. 6 P53, PTEN, and NF1 protein structure. p53, PTEN, and NF1 protein structure from $\mathrm{N}$-Terminal to $\mathrm{C}$-Terminal with localization of detected mutations. TAD- transcriptional activation domain, PRDproline-rich domain, DBD- DNA-binding domain, NLS- nuclear localization signal, TS- tetramerization domain, BD- basic domain, PBD- PIP2 binding domain, PD-phosphatase domain, C2D- C2 domain, CTT- C-terminal tail, PDZ-PSD95/Disc large/Zonula occludens-1 domain, CSRD-Cysteine/Serine-rich domain, TBDtubulin-binding domain, GRD- GTPase-activation protein-related domain, SEC-14- SEC-14 domain, PH- pleckstrin homology domain, CTD-Carboxy terminal domain, SBD-Syndecan-binding domain
Fig. 7 Signaling networks regulated by NF1, P53 and PTEN proteins. Schematic presentation of signaling network with pathways regulated by NF1, P53, and PTEN proteins

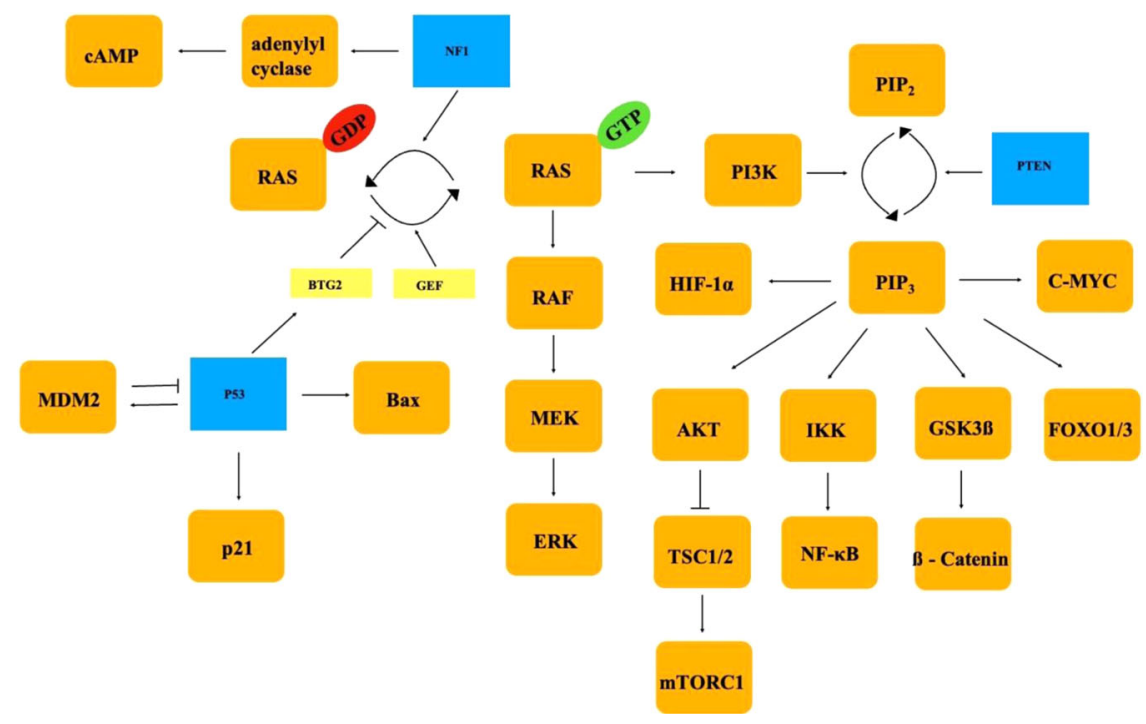

\section{Methods}

\section{Microscopy and immunochemistry}

Tumor tissue was fixed in $4 \%$ paraformaldehyde directly after surgical resection, dehydrated, embedded in paraffin, and then sectioned at $2 \mu \mathrm{m}$ according to standard lab protocols. For all immunohistochemical stains paraffin-embedded tissue was deparaffinized, rehydrated. All immunohistochemical stainings were performed using automatic staining machines (Ventana BenchMark TX and Ventana Discovery Ultra), Roche Diagnostics, Mannheim, Germany). The following primary antibodies were used: $\operatorname{ATRX}(1: 400$, HPA001906, Atlas Antibodies, Bromma, Sweden), GH (1:1000, PA0704, Leica Biosystems, Buffalo Grove, IL, United States), Prolactin(1:1000, ab11301, Abcam, Cambridge, UK), TSH(1:10000, Epredia, Portsmouth, NH,
United States), ACTH(1:500, RP045, Diagnostic BioSystems, Hanhgzhou, China), FSH(1:200, M3504, DAKO, Glostrup, Denmark), LH(1:300, M3502, DAKO, Glostrup, Denmark), Pit-1(1:200, HPA041646, Sigma-Aldrich, Taufkirchen, Germany), T-pit(1:1500, AMAb91409, Atlas Antibodies, Bromma, Sweden), TTF-1(1:50, M3575, DAKO, Glostrup, Denmark, Ki-67(1:750, 275R-15, Cell Marque, Rocklin, CA, United States), p53(1:800, M7001, DAKO, Glostrup, Denmark), chromogranin(1:800, M0869, DAKO, Glostrup, Denmark, synaptophysin (1:500, M7315, DAKO, Glostrup, Denmark), EGFRvIII (1:250, T170B620, Absolute Antibody, Oxford, Great Britain).

\section{DNA isolation}

The tissue was further sectioned 10 times at $10 \mu \mathrm{m}$ according to standard lab protocol. HE stains were utilized 
for the selection of tumor area. Tumor tissue was then manually microdissected using a fine needle under an inverted microscope. The DNA was isolated using Maxwell $^{\circledast}$ RSC DNA FFPE Kit (AS1450, Promega).

\section{Next-generation-sequencing}

DNA panel sequencing was done using a self-customized targeted panel, manufactured by Qiagen (CDHS-21330Z424). This panel targets the complete coding regions and splice-sites of six genes (ATRX, EGFR, NF1, NF2, PTEN, TP53), as well as mutation hotspots of further 14 genes (AKT, BRAF, CTNNB1, FGFR1, FGFR2, H3F3A, HIST1H3B, HIST1H3C, IDH1, IDH2, KRAS, PI3CA, PIK3R1, TERT-promoter). The library was constructed according to the manufacturer's instructions. Sequencing was done on an Illumina MiniSeq sequencing system (paired-end, $2 \times 151 \mathrm{bp}$, average coverage 500x). Data were analyzed with the Qiagen CLC Genomics workbench, using a self-customized workflow. Variants were annotated with information from the 1000 genome project, dbSNP, ClinVar and COSMIC. Only variants with an allele frequency $\geq 5 \%$ and a total target coverage of $\geq 40 \mathrm{x}$ were analyzed further. Variants not annotated by ClinVar were additionally analyzed with VarSome (www.varsome.com).

\section{Sanger sequencing}

Primers previously described by Sbiera et al. were used for both amplification and sequencing the specific regions of USP8 and USP48 genes [37]. A PCR reaction volume of $25 \mu \mathrm{l}$ containing $40 \mathrm{ng}$ of template DNA, $0.1 \mu \mathrm{M}$ of each primer, $100 \mu \mathrm{M}$ dNTPs (deoxyribonucleotide triphosphates), Dream Taq polymerase buffer, and 1.25 U Dream Taq DNA Polymerase was prepared and amplified after initial denaturation at $95^{\circ} \mathrm{C}$ for $3 \mathrm{~min}$ followed by 35 cycles of denaturation at $95^{\circ} \mathrm{C}$ for $30 \mathrm{~s}$, annealing at $55^{\circ} \mathrm{C}$ for $45 \mathrm{~s}$, and elongation at $72{ }^{\circ} \mathrm{C}$ for $60 \mathrm{~s}$. PCR products were sequenced using Mix2Seq Kit NightXpress and performed by Eurofinsgenomics.

Acknowledgements The tumors included in the present study were drawn from the German Registry of Pituitary Tumors which is sponsored by Novartis Pharma GmbH (Nürnberg), Novo Nordisk Pharma $\mathrm{GmbH}$ (Mainz), Phizer Pharma GmbH (Berlin), and Ipsen Pharma $\mathrm{GmbH}$ (Munich).

Funding Open Access funding enabled and organized by Projekt DEAL.

\section{Compliance with ethical standards}

Conflict of interest All authors (Piotr Sumislawski, Roman Rotermund, Silke Klose, Anne Lautenbach, Annika K. Wefers, Celina Soltwedel, Behnam Mohammadi, Frank Jacobsen, Christian Mawrin, Jörg Flitsch, Wolfgang Saeger) declare no conflict of interest.
Ethical approval All procedures performed in studies involving human participants were in accordance with the ethical standards of the institutional and/or national research committee and with the 1964 Helsinki declaration and its later amendments or comparable ethical standards (a separate ethic review and permission of a local committee was not necessary according to $\S 12$ to the Hamburgisches Krankenhausgesetz, Hamburg, Germany). We currently state that written informed consent including medical photographs was obtained from the participant for the publication of this case report.

Publisher's note Springer Nature remains neutral with regard to jurisdictional claims in published maps and institutional affiliations.

Open Access This article is licensed under a Creative Commons Attribution 4.0 International License, which permits use, sharing, adaptation, distribution and reproduction in any medium or format, as long as you give appropriate credit to the original author(s) and the source, provide a link to the Creative Commons license, and indicate if changes were made. The images or other third party material in this article are included in the article's Creative Commons license, unless indicated otherwise in a credit line to the material. If material is not included in the article's Creative Commons license and your intended use is not permitted by statutory regulation or exceeds the permitted use, you will need to obtain permission directly from the copyright holder. To view a copy of this license, visit http://creativecommons. org/licenses/by/4.0/.

\section{References}

1. P.J. Pernicone, B.W. Scheithauer, T.J. Sebo et al., Pituitary carcinoma: A clinicopathologic study of 15 cases. Cancer. (1997). https://doi.org/10.1002/(SICI)1097-0142(19970215)79:43.0. $\mathrm{CO} ; 2-3$

2. F. Yoo, E.C. Kuan, A.P. Heaney, M. Bergsneider, M.B. Wang, Corticotrophic pituitary carcinoma with cervical metastases: case series and literature review. Pituitary. (2018). https://doi.org/10. 1007/s11102-018-0872-8.

3. J.M. van der Zwan, S. Mallone, B. van Dijk et al., Carcinoma of endocrine organs: Results of the RARECARE project. Eur. J. Cancer. (2012). https://doi.org/10.1016/j.ejca.2012.01.029

4. T.M. Hansen, S. Batra, M. Lim et al., Invasive adenoma and pituitary carcinoma: A SEER database analysis. Neurosurg. Rev. (2014). https://doi.org/10.1007/s10143-014-0525-y

5. P.N. Elsässer Imboden, F.X. Borruat, N. de Tribolet, K. MeagherVillemure, A. Pica, F. Gomez, Non-functioning pituitary carcinoma. Pituitary. (2004). https://doi.org/10.1007/s11102-005-3411-3

6. R.V. Lloyd, R.Y. Osamura, G.R.J. Klöppel, WHO Classification of Tumours of Endocrine Organs, 4th edn. (WHO-OMS, Lyon; 2017).

7. G.A. Kaltsas, A.B. Grossman, Malignant pituitary tumours. Pituitary. (1998). https://doi.org/10.1023/A:1009975009924

8. O. Casar-Borota, H.B. Boldt, B.E. Engström, et al., Corticotroph aggressive pituitary tumors and carcinomas frequently harbor ATRX mutations. J. Clin. Endocrinol. Metabolism 106(4), 1183 (2021). https://doi.org/10.1210/CLINEM/DGAA749

9. D.K. Lüdecke, M. Buchfelder, R. Fahlbusch, H.J. Quabbe, S. Petersenn, W. Saeger, Pathohistological classification of pituitary tumors: 10 years of experience with the German Pituitary Tumor Registry. Eur. J. Endocrinol. 156(2), 203-216 (2007). https://doi. org/10.1530/eje.1.02326

10. Heaney A.P. Pituitary carcinoma: Difficult diagnosis and treatment. J. Clin. Endocrinol. Metabolism. 96(12), 3649-3660 (2011). https://doi.org/10.1210/jc.2011-2031 
11. O. Casar-Borota, J. Botling, D. Granberg, et al., Serotonin, ATRX, and DAXX expression in pituitary adenomas: markers in the differential diagnosis of neuroendocrine tumors of the sellar region. Am. J. Surg. Pathol. 41(9), 1238-1246 (2017). https://doi. org/10.1097/PAS.0000000000000908

12. N. Tufton, F. Roncaroli, I. Hadjidemetriou, et al., Pituitary carcinoma in a patient with an SDHB mutation. Endocrine Pathol. 28 (4), 320 (2017). https://doi.org/10.1007/S12022-017-9474-7

13. Y. Tanizaki, L. Jin, B.W. Scheithauer, K. Kovacs, F. Roncaroli, R. v. Lloyd, P53 gene mutations in pituitary carcinomas. Endocrine Pathol. (2007). https://doi.org/10.1007/s12022-0079006-y

14. L. Pei, S. Melmed, B. Scheithauer, K. Kovacs, D. Prager, H-ras mutations in human pituitary carcinoma metastases. J. Clin. Endocrinol. Metabol. 78(4), 842-846 (1994). https://doi.org/10. 1210/jcem.78.4.8157709

15. D. Bengtsson, P. Joost, C. Aravidis, et al., Corticotroph pituitary carcinoma in a patient with Lynch Syndrome (LS) and pituitary tumors in a nationwide LS cohort. J. Clin. Endocrinol. Metabolism 102(11), 3928-3932 (2017). https://doi.org/10.1210/jc.201701401

16. F. Guo, G. Wang, F. Wang, D. Xu, X. Liu, Identification of novel genes involved in the pathogenesis of an ACTH-secreting pituitary carcinoma: A case report and literature review. Front. Oncol. 8, 510 (2018). https://doi.org/10.3389/FONC.2018.00510

17. B.T. Ragel, W.T. Couldwell, Pituitary carcinoma: a review of the literature. Neurosurg. Focus. (2004). https://doi.org/10.3171/foc. 2004.16.4.8

18. A. Lacroix, F. Gu, J. Schopohl, et al., Pasireotide treatment significantly reduces tumor volume in patients with Cushing's disease: results from a Phase 3 study. Pituitary 23(3), 203-211 (2020). https://doi.org/10.1007/s11102-019-01021-2

19. A. Heaney, Management of aggressive pituitary adenomas and pituitary carcinomas. J. Neuro-Oncol. (2014). https://doi.org/10. 1007/s11060-014-1413-6

20. P. Kamenický, C. Droumaguet, S. Salenave et al., Mitotane, metyrapone, and ketoconazole combination therapy as an alternative to rescue adrenalectomy for severe ACTH-dependent Cushing's syndrome. J. Clin. Endocrinol. Metabolism. (2011). https://doi.org/10.1210/jc.2011-0536

21. C.M. Heaphy, Bi.L. Wenya, et al., Telomere length alterations and ATRX/DAXX loss in pituitary adenomas. Modern Pathol. 33, 1475-1481 (2020). https://doi.org/10.1038/s41379-020-0523-2

22. H. Solomon, Y. Buganim, I. Kogan-Sakin, et al., Various p53 mutant proteins differently regulate the ras circuit to induce a cancer-related gene signature. J. Cell Sci. 125(13), 3144-3152 (2012). https://doi.org/10.1242/jcs.099663

23. Y. Buganim, H. Solomon, Y. Rais, et al., p53 regulates the ras circuit to inhibit the expression of a cancer-related gene signature by various molecular pathways. Cancer Res. 70(6), 2274-2284 (2010). https://doi.org/10.1158/0008-5472.CAN-09-2661

24. K.L. Harms, X. Chen, The functional domains in 553 family proteins exhibit both common and distinct properties. Cell Death Differentiation 13(6), 890-897 (2006). https://doi.org/10.1038/sj.cdd.4401904

25. H. Scrable, T. Sasaki, B. Maier, $\Delta \mathrm{Np} 53$ or $\mathrm{p} 44$ : Priming the $\mathrm{p} 53$ pump. Int. J. Biochem. Cell Biol. 37(5), 913-919 (2005). https:// doi.org/10.1016/j.biocel.2004.11.014

26. J. Zhu, S. Zhang, J. Jiang, X. Chen, Definition of the p53 functional domains necessary for inducing apoptosis. J. Biol. Chem. 275(51), 39927-39934 (2000). https://doi.org/10.1074/jbc. M005676200
27. F. D'Angelo, M. Ceccarelli, Tala et al., The molecular landscape of glioma in patients with Neurofibromatosis 1. Nat. Med. (2019). https://doi.org/10.1038/s41591-018-0263-8

28. S. Ben-Salem, A.M. Al-Shamsi, B.R. Ali, L. Al-Gazali, The mutational spectrum of the NF1 gene in neurofibromatosis type I patients from UAE. Child's Nervous Syst. (2014). https://doi.org/ 10.1007/s00381-013-2352-9

29. N. Ratner, S.J. Miller, A RASopathy gene commonly mutated in cancer: The neurofibromatosis type 1 tumour suppressor. Nat. Rev. Cancer 15(5), 290-301 (2015). https://doi.org/10.1038/nrc3911

30. L. Salvatore, M.A. Calegari, F. Loupakis, et al., PTEN in colorectal cancer: Shedding light on its role as predictor and target. Cancers 11 (11), 1765 (2019). https://doi.org/10.3390/cancers 11111765

31. A. Lalatsa, Y. Sun, J.I. Gamboa, S. Knafo, Preformulation studies of a stable PTEN-PDZ lipopeptide able to cross an in vitro bloodbrain-barrier model as a potential therapy for Alzheimer's disease. Pharm. Res. 37(10), 1-13 (2020). https://doi.org/10.1007/s11095020-02915-8

32. E. Castellano, J. Downward, Ras interaction with PI3K: More than just another effector pathway. Genes and Cancer. 2(3), 261-274 (2011). https://doi.org/10.1177/1947601911408079

33. F. Luongo, F. Colonna, F. Calapà, S. Vitale, M.E. Fiori, R. De Maria, Pten tumor-suppressor: The dam of stemness in cancer. Cancers. (2019). https://doi.org/10.3390/cancers11081076.

34. G. Xue, B.A. Hemmings, PKB/akt-dependent regulation of cell motility. J. Natl Cancer Institute 105(6), 393-404 (2013). https:// doi.org/10.1093/jnci/djs648

35. Bazzichetto C., Conciatori F., Pallocca M., et al., Pten as a prognostic/predictive biomarker in cancer: An unfulfilled promise? Cancers. (2019). https://doi.org/10.3390/cancers11040435

36. L.G. Pérez-Rivas, M. Theodoropoulou, T.H. Puar, et al., Somatic USP8 mutations are frequent events in corticotroph tumor progression causing Nelson's tumor. Eur. J. Endocrinol. 178(1), 57-63 (2018). https://doi.org/10.1530/EJE-17-0634

37. S. Sbiera, L.G. Perez-Rivas, L. Taranets, et al., Driver mutations in USP8 wild-type Cushing's disease. Neuro-Oncology 21(10), 1273 (2019). https://doi.org/10.1093/NEUONC/NOZ109

38. C.P. Miermeister, S. Petersenn, M. Buchfelder, et al., Histological criteria for atypical pituitary adenomas-data from the German pituitary adenoma registry suggests modifications. Acta Neuropathol. Commun. 3, 50 2015). https://doi.org/10.1186/S40478-015-0229-8

39. R. Yaeger, R.B. Corcoran, Targeting alterations in the RAF-MEK pathway. Cancer Discov. 9(3), 329-341 (2019). https://doi.org/10. 1158/2159-8290.CD-18-1321

40. U. Degirmenci, M. Wang, J. Hu, Targeting aberrant RAS/RAF/ MEK/ERK signaling for cancer therapy. Cells 9(1), 198 (2020). https://doi.org/10.3390/cells9010198

41. A.S. Alzahrani. PI3K/Akt/mTOR inhibitors in cancer: At the bench and bedside. Semin. Cancer Biol. (2019). https://doi.org/10. 1016/j.semcancer.2019.07.009

42. C. Yang, G. Lou, W.-L. Jin, The arsenal of TP53 mutants therapies: neoantigens and bispecific antibodies. Signal Transduct. Targeted Ther. 6(1), 1-2 (2021). https://doi.org/10.1038/s41392021-00635-y

43. S. Haase, M.B. Garcia-Fabiani, S. Carney, et al., Mutant ATRX: uncovering a new therapeutic target for glioma. Expert Opin. Ther. Targets 22(7), 599 (2018). https://doi.org/10.1080/ 14728222.2018.1487953

44. C. Dai, S. Liang, B. Sun, J. Kang. The progress of immunotherapy in refractory pituitary adenomas and pituitary carcinomas. Front. Endocrinol. (2020). https://doi.org/10.3389/FENDO.2020.608422 